\title{
Determination of Daidzein in Rat Plasma by LC
}

By: Xi Li, Qi Shen, Dan Yuan, Ainiu Ma, and Wei Jia

Li, X., Shen, Q., Yuan, D., Ma, A., \& Jia, W. (2008). Determination of daidzein in rat plasma by LC. Chromatographia, 68(3-4), 201-205.

***Note: This version of the document is not the copy of record. Made available courtesy of Springer Verlag. The original publication is available at www.springerlink.com, Link to Article: http://www.springerlink.com/content/7t323658715j3664/

\begin{abstract}
:
Daidzein (4',7-dihydroxylisoflavone), a water-insoluble isoflavone, is mainly present in leguminous plants. This study was aimed at investigating the absorption characteristics of daidzein across the intestinal membranes. Borneol has been used to enhance the intestinal absorption and bioavailability of daidzein. We chose an in vitro diffusion chamber system using isolated rat intestinal membranes as a model. A sensitive, accurate and reliable LC method was developed and validated to determine daidzein in rat plasma. A linear relationship for daidzein was found in the range of $20-800 \mathrm{ng} \mathrm{mL}^{-1}$. The mean absolute recoveries of daidzein determined over three concentrations were $89.8 \pm 4.8,91.3 \pm 2.8$ and $95.4 \pm 1.7 \%$. The coefficients of variation for inter-day and intra-day assay were found to be less than $6.1 \%$. The plasma concentration of daidzin following oral administration was significantly increased by coadministration of borneol in rats, and a 1.5-fold enhancement of relative bioavailability of daidzein was observed as compared to daidzein administered alone.
\end{abstract}

Article:

INTRODUCTION

Daidzein (Figure 1) (4',7-dihydroxylisoflavone), a water-insoluble isoflavone, is mainly present in leguminous plants, especially in soybeans, soy foods and Pueraria lobata Ohwi (Leguminosae) $[1,2]$. It has already been demonstrated that diadzein can reduce breast cancer occurrence, and may play a key role in protection against colon cancer [3]. More recently, Wilcox and Blumenthal [4] have hypothesized that isoflavones might reduce the aggregation of platelets at the sites of arterial injury associated with atherosclerotic development [5].

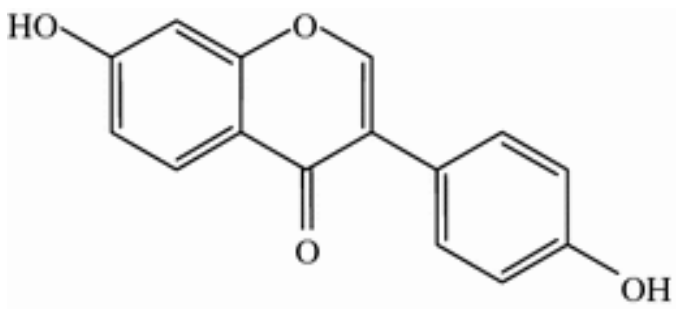

Figure 1: Structure of daidzein 
Nevertheless, the occurrence of any beneficial effects of bioactive compounds is mainly related to their ability to be absorbed in the intestine. Only limited studies on absorption, metabolism, and distribution of isoflavones are available [6-11]. Studies of Setchell et al. [12, 13] on isoflavone bioavailability in healthy women, showing a curvilinear relationship between dietary intake and plasma levels. We focused our attention on intestinal absorption characteristics of daidzein because data regarding absorption of this isoflavone are very limited. Borneol, has been used in our work to enhance the intestinal absorption and bioavailability of this poorly watersoluble isoflavone.

Oral administration is the preferred route by virtue of its convenience and better compliance. However, the development of this delivery system is considered to be a great challenge due to the poor water-solubility, poor permeability and rapid metabolism of some drugs. A variety of formulation strategies has been developed to improve the solubility and bioavailability of such drugs. Several approaches such as absorption enhancers [14, 15], chemical modification [16, 17] and dosage forms $[18,19]$ have been explored in order to attain peroral delivery of drugs. Of these approaches, the use of absorption enhancers has often been adapted to enhance the intestinal absorption $[15,20]$. Some studies have shown that borneol could improve the oral bioavailability of some drugs [21].

In this study, we have investigated the absorption characteristics of daidzein across the intestinal membranes. The influence of borneol as an absorption enhancer on the intestinal absorption and oral bioavailability of daidzein was also investigated in rats.

\section{EXPERIMENTAL}

\section{Chemicals and Reagents}

Diethyl ether, PEG400, borneol and menthol were purchased from the Shanghai Chemical Reagents Institute (Shanghai, China). Daidzein was provided by Qingze Co. (Nanjing, China). The purity was $98 \%$, verified using LC.

\section{Chromatographic Conditions}

LC was conducted on Waters (Waters Corp., MA, USA) equipped with 1525 controller pumps, a Waters 2487 detector and configured to Millennium 3.2 software. Sample was loaded onto the column by means of a Waters 717plus autosampler. Analysis was on an Elite $5 \mu \mathrm{m} \mathrm{C}_{18}$ column $(150 \times 4.6 \mathrm{~mm}$ i.d., Dalian, China). The mobile phase was methanol in distilled deionized water

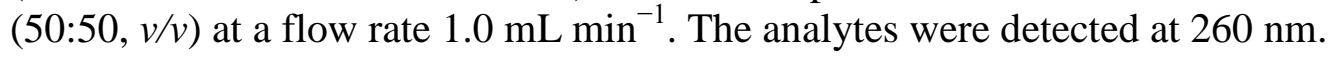

\section{Preparation of Stock Solutions and Working Solutions}

Stock solutions of daidzein were prepared in methanol (at a concentration of $1 \mathrm{mg} \mathrm{mL}^{-1}$ ) and stored at $4{ }^{\circ} \mathrm{C}$. Plasma samples were stored at $-20^{\circ} \mathrm{C}$ until required. Working solutions were prepared on the day of an analysis by further dilution of the stock solutions with methanol.

\section{Animal Handling}

Healthy male Sprague-Dawley rats (200-250 g) were purchased from the Animal Resources Center, Shanghai Jiaotong University, China. Rats were kept in a room under controlled temperature $\left(22 \pm 1^{\circ} \mathrm{C}\right)$ and automatic day-night rhythm (12 h-cycle) and housed on wire-bottom cages with paper underneath. Ethical approval of this study was obtained from the Ethical 
Committees of Shanghai Jiaotong University. Rats were provided with free access to tap water and food. After overnight fasting, the animals were anesthetized with diethyl ether. The intestine was exposed through a midline abdominal incision, removed, and washed in $0.9 \%$ sterile sodium chloride solution. Intestinal segments, excluding Peyer's patches, were isolated and immersed in $0.9 \%$ sterile sodium chloride solution.

\section{Absorption Experiment}

The absorption of daidzein across the rat intestinal membrane was studied with a diffusion chamber (Corning Coster Corp.) [22-24]. Segments were cut open and the intestinal sheets were mounted onto the pins of the cell, and the half-cells were clamped together. Daidzein solutions were freshly prepared by dissolving in DMSO, and were diluted in phosphate buffer solution to yield a final concentration of $20 \mu \mathrm{g} \mathrm{mL}^{-1}$. The final concentration of DMSO in phosphate buffer solution was $1 \%(v / v)$. Drug solution $(7 \mathrm{~mL})$ was added to the donor site, whereas the same volume of drug-free buffer was added to the opposite site. The temperature of the intestinal membranes was maintained at $37{ }^{\circ} \mathrm{C}$, and both fluids were circulated by gas lift with $95 \% \mathrm{O}_{2} / 5 \%$ $\mathrm{CO}_{2}$. During the absorption studies, aliquots were taken from the receptor chamber at predetermined time up to approximately $2 \mathrm{~h}$. The receptor chamber samples were replaced with an equal volume of appropriate buffer. The permeated drugs were assayed. The apparent permeability coefficients $\left(P_{\text {app }}\right)$ of the drug were calculated from the slope of the linear portion of the permeability-time profiles by the relationship $P_{\text {app }}=\left(\mathrm{d} X{ }_{\mathrm{R}} / \mathrm{d} t\right) \times\left(1 / A \mathrm{C}_{0}\right)$, where $P$ app is the apparent permeability coefficient, $X_{\mathrm{R}}$ is the amount of drug in the receptor side, $A$ is the diffusion area, and $C_{0}$ is the initial concentration of drug on the donor side. Efflux ratio was used to evaluate the extent of efflux [25-29].

\section{Pharmacokinetic Study}

Eight male Sprague-Dawley rats were fasted overnight with free access to water before drug administration. Daidzein was suspended in 20\% PEG400 solution as a control sample, borneol was added to the daidzein suspension and the final suspension was administered orally (10 mg $\mathrm{kg}^{-1}$ of daidzein) with a blunt needle via the esophagus into the stomach. Subsequently, blood samples $(200 \mu \mathrm{L})$ were collected into heparinized micro-centrifuge tubes (100 IU mL ${ }^{-1}$ blood) from the caudal vein at $0.17,0.25,0.5,0.75,1,1.5,2,4,6$ and 8 h respectively. Blood samples were centrifuged for $5 \mathrm{~min}$ at $5,000 \mathrm{~g}$ and the daidzein concentrations in the plasma were determined by LC. The area under the plasma concentration versus time curve (AUC) from time zero to final sampling time $(12 \mathrm{~h})$ was calculated by the linear trapezoidal rule. The peak plasma concentration $\left(C_{\max }\right)$ and the time to reach the peak plasma concentration $\left(T_{\max }\right)$ were observed from the experimental data.

$100 \mu \mathrm{L}$ plasma was mixed with $200 \mu \mathrm{L}$ acetonitrile in an Eppendorf tube. The tubes were vortexed for $1 \mathrm{~min}$ and centrifuged at 5,000 $\mathrm{g}$ for $10 \mathrm{~min}$, and $20 \mu \mathrm{L}$ of the resulting supernatant was injected into the LC system.

\section{Standard Solutions for Linearity Testing}

Blank plasma was prepared from heparinized whole-blood samples collected from rats and stored at $-20^{\circ} \mathrm{C}$. After thawing, stock solution of daidzein was added to yield final concentrations of 20,50,100, 200, 500 and $800 \mathrm{ng} \mathrm{mL}^{-1}$. The samples were then prepared for analysis as described above. 


\section{Stability}

The stability of daidzein was assessed in spiked plasma samples stored at $-20{ }^{\circ} \mathrm{C}$ for 1 month and at ambient temperature for at least $12 \mathrm{~h}$. The stability of stock solutions stored at $-20^{\circ} \mathrm{C}$ was determined for up to 1 month by injecting appropriate dilutions in methanol on day 1, 15 and 30 and comparing their peak areas with fresh stock solution prepared on the day of analysis. Samples were considered to be stable, if the assay values were within the acceptable limits of accuracy and precision, the percent deviation from the nominal concentration (accuracy) and the relative standard deviation must be $\pm 20 \%$ and less than $20 \%$, respectively.

\section{Selectivity}

Control rat plasma was assessed by the procedure as described above and compared with plasma samples to evaluate the selectivity of the method.

\section{Precision and Accuracy}

The precision and accuracy of the method were examined by adding known amounts of daidzein to pool plasma (quality control samples). For intra-day precision and accuracy of daidzein concentration and retention time, five replicate quality control samples at each concentration were assayed on the same day. The inter-day precision and accuracy were evaluated on three different days.

\section{Limit of Quantification (LOQ) and Recovery}

The limit of quantification (LOQ, $\mathrm{S} / \mathrm{N}=10$ ) was determined by establishing the minimum concentration of analyte in plasma that could be quantified with acceptable accuracy and precision under the stated experimental conditions. The absolute recovery was calculated for three different concentrations of daidzein $\left(20,100\right.$ and $500 \mathrm{ng} \mathrm{mL}^{-1}$ ) as the mean $( \pm \mathrm{SD})$ of three samples by comparing peak areas of directly injected analytes solutions with peak areas of extracted plasma samples.

\section{Statistical Analysis}

Statistical evaluations were performed by Student $t$-test of the paired observations to analyze the different concentrations of daidzein. $P$ values $<0.05$ were considered to indicate significant differences. Data are expressed as means $\pm \operatorname{SD}(n=3)$.

\section{RESULTS}

\section{Method Validation}

Under the chromatographic conditions described, daidzein peaks were well resolved in standard mixtures and endogenous plasma components did not give any interfering peaks. Figure 2 shows typical chromatograms of blank plasma in comparison with spiked samples analyzed for a pharmacokinetic study. The average retention time of daidzein was $6.8 \mathrm{~min}$. The calibration curve for the determination of daidzein in plasma was linear over the range $20-800 \mathrm{ng} \mathrm{mL}^{-1}$. The linearity of this method was statistically confirmed. The following regression equations were obtained: $A=164.9 C\left(\mathrm{ng} \mathrm{mL}^{-1}\right)+60.5, r=0.9998$. The absolute analytical recovery of daidzein, determined at three concentrations $\left(20,100\right.$ and $\left.500 \mathrm{ng} \mathrm{mL}^{-1}\right)$, were $89.8 \pm 4.8,91.3 \pm 2.8$ and $95.4 \pm 1.7 \%(n=3)$. The limit of quantification (LOQ), as previously defined, was $15 \mathrm{ng} \mathrm{mL}{ }^{-1}$. This is sensitive enough for drug monitoring and other purposes such as pharmacokinetic studies. 
We assessed the precision of the method by repeated analysis of plasma specimens containing known concentrations of daidzein; the intra-day RSD values of daidzein concentration were less than $4.6 \%$, inter-day RSD values were less than $6.1 \%$. We also assessed the reproducibility of the retention time by repeated analysis of plasma specimens containing daidzein, the intra-day RSD values of retention time were less than $1.0 \%$, inter-day RSD values were less than $1.5 \%$, which was acceptable for the routine measurement. Stability was determined for spiked plasma samples under the conditions as previously described. The results showed that the samples were stable under the conditions used.
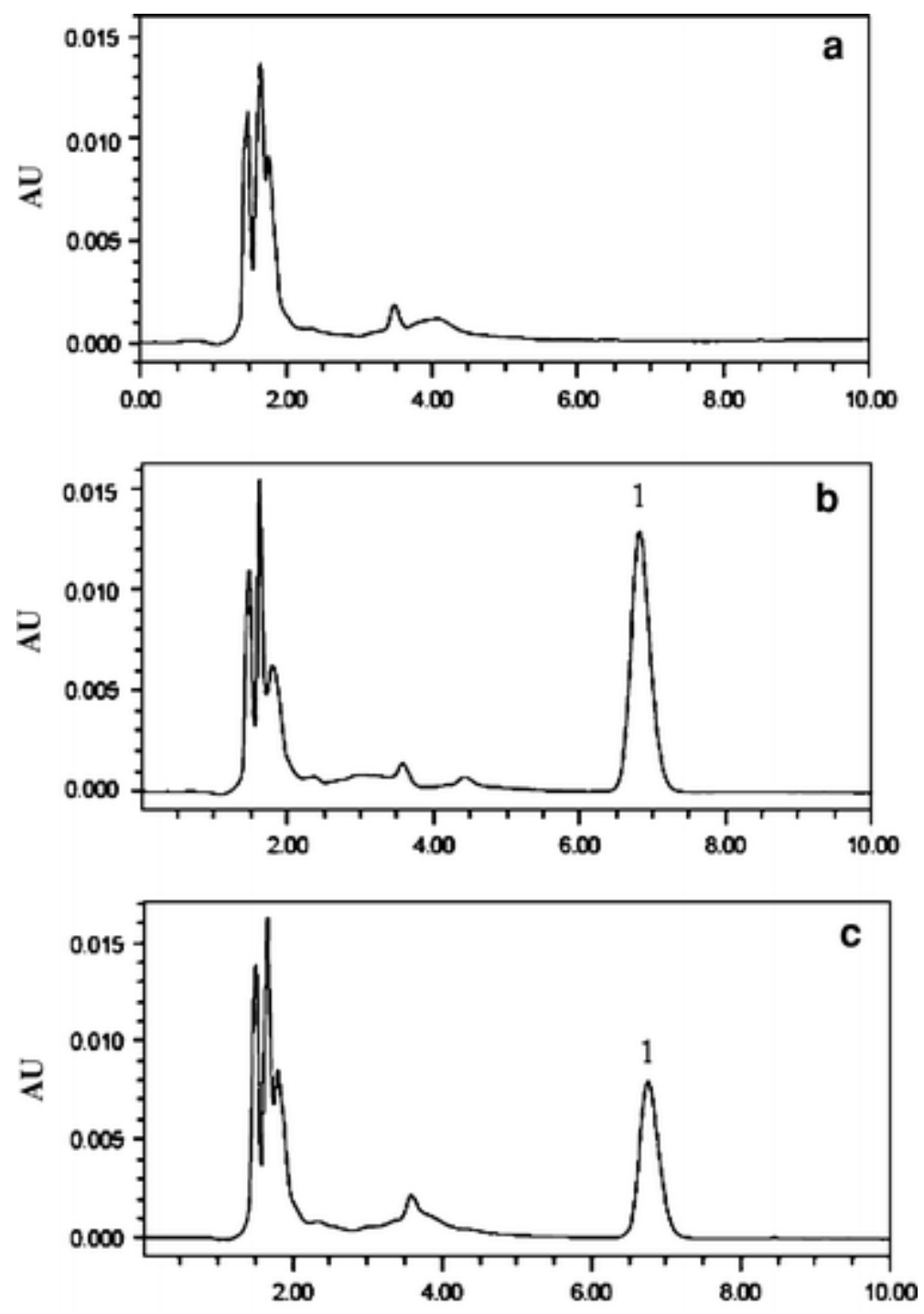

Time(min)

Figure 2: Chromatograms of a blank plasma, b blank plasma spiked with daidzein, c plasma sample. Peak 1 daidzein $\left(t_{\mathrm{R}}=6.8 \mathrm{~min}\right)$

\section{Absorption Characteristics of Daidzein Across the Intestinal Membranes}

Effect of $\mathbf{p H}$ on the Absorption of Daidzein. Transepithelial absorption of daidzein across the rat intestinal membrane was examined at $\mathrm{pH}$ 5.5, 6.0, 6.5, 7.0 and 7.4; values at $\mathrm{pH} 5.5$ were 
used as controls. The studies were performed at a concentration of $20 \mu \mathrm{g} \mathrm{mL}^{-1}$ of daidzein. Effect of $\mathrm{pH}$ on transepithelial absorption is shown in Figure 3. It was found that $\mathrm{pH}$ dependence was observed for the absorptive of daidzein in the $\mathrm{pH}$ range of 5.5-7.4. The absorption $P$ app (mucosal to serosal) of daidzein changed significantly over this $\mathrm{pH}$ range.

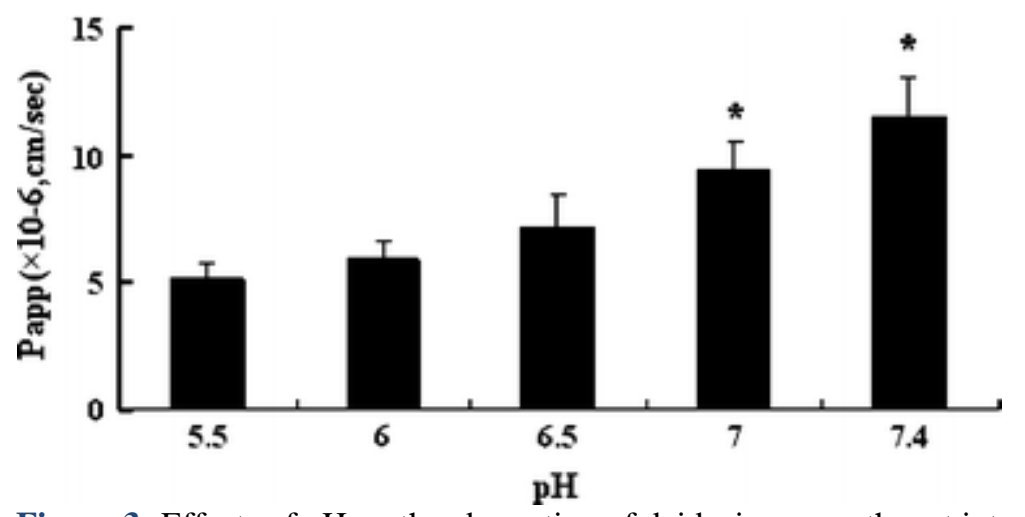

Figure 3: Effects of $\mathrm{pH}$ on the absorption of daidzein across the rat intestinal membrane. Data are the mean \pm SD from at least three determinations. ${ }^{*} P<0.05$ from the $\mathrm{pH} 5.5$ control with Dunnett $t$-test

Effect of Absorption Enhancers on the Absorption of Daidzein. Borneol as an absorption enhancer was added to the daidzein solution, to a final concentration of borneol of $20 \mu \mathrm{g} \mathrm{mL}^{-1}$. Figure 4 shows the time course of absorption (mucosal to serosal) of daidzein across the rat intestinal membrane with and without borneol. Addition of borneol to mucosal side increasd the absorption of daidzein significantly.

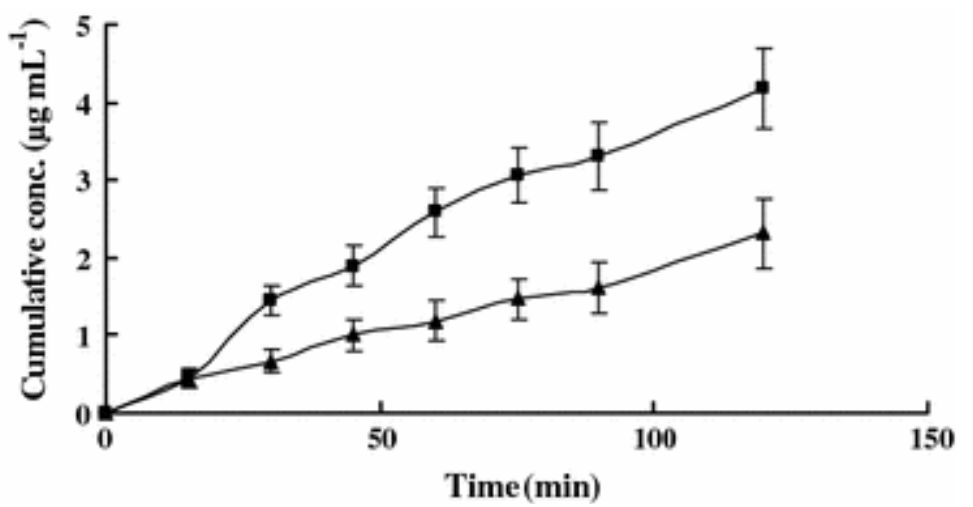

Figure 4: Time course of absorptive of daidzein(- $\left.\boldsymbol{\Lambda}_{-}\right)$and effect of borneol on the absorption of daidzein(- $\left.\mathbf{-}-\right)$ across the rat intestinal membrane. Data are the mean \pm SD from at least three determinations

\section{Bioavailability Study and Pharmacokinetic Analysis}

Plasma concentration-time profiles of daidzein given orally as a suspension $\left(10 \mathrm{mg} \mathrm{kg} \mathrm{of}^{-1}\right.$ daidzein) alone or in combination with borneol (10 $\mathrm{mg} \mathrm{kg}^{-1}$ of borneol), in Sprague-Dawley rats are given in Figure 5. A significant increase in daidzein plasma concentration was observed after oral administration with borneol. 


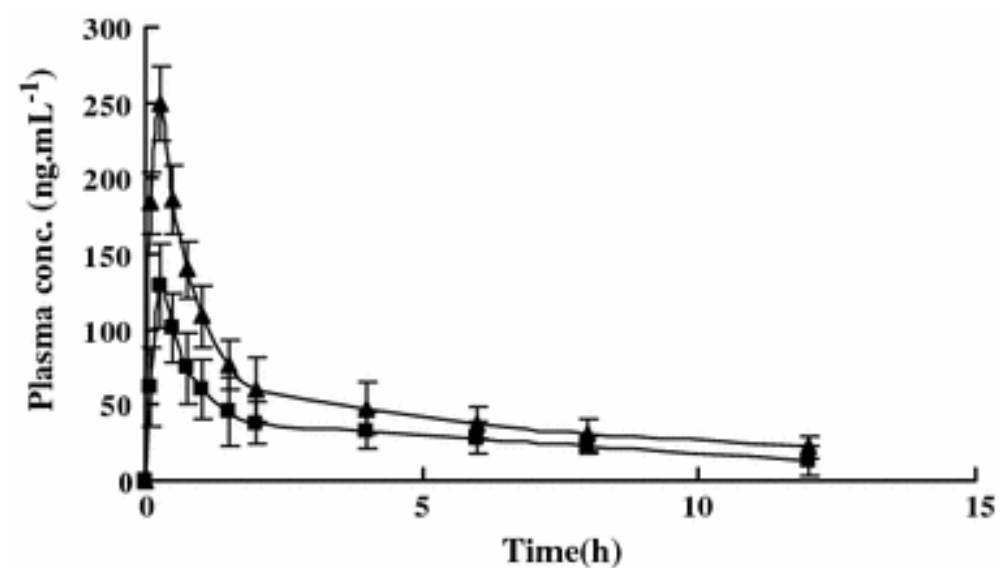

Figure 5: Plasma concentration-time profiles of daidzein in rats after oral administration of daidzein $\left(10 \mathrm{mg} \mathrm{mL}^{-1}\right)$ alone(-m-) and in combination with borneol(- $\mathbf{\Delta}-)$. Data are the means $\pm \operatorname{SD}(n=4)$

Table 1 shows the pharmacokinetic parameters of daidzein, given alone or in combination with borneol. $C$ max of daidzein/borneol was 1.9 times higher than when daidzein was administered alone. Relative bioavailability of daidzein/borneol was 1.5 times higher compared to daidzein suspension.

Table 1: Pharmacokinetic parameters of daidzein after oral $\left(10 \mathrm{mg} \mathrm{kg}^{-1)}\right.$ administration in rats

\begin{tabular}{|c|c|c|c|}
\hline Administration & $C_{\max }\left(\mathrm{ng} \mathrm{mL^{-1 }}\right)$ & $T_{\max }(\mathbf{h})$ & $\mathrm{AUC}_{0-12}\left(\mathrm{ng} \mathrm{h} \mathrm{mL} \mathrm{mL}^{-1}\right)$ \\
\hline Oral daidzein only & $128.57 \pm 27.64$ & $0.33 \pm 0.04$ & $331.27 \pm 115.76$ \\
\hline Oral daidzein + borneol & $249.78 \pm 24.24 *$ & $0.25 \pm 0.07 \mathrm{NS}$ & $512.03 \pm 146.53 *$ \\
\hline
\end{tabular}

\section{CONCLUSION}

Daidzein preparations and nutritional supplements containing daidzein are widely consumed for their potential health effects. However, the oral bioavailability of daidzein is very poor, which limits its beneficial effects [30-33]. We investigated the absorption characteristics of daidzein across the intestinal membranes, with and without borneol as an absorption enhancer.

The method of analysis developed by us is well suited for routine application in the clinical laboratory because of its speed and the simple extraction procedure required which only involves protein precipitation.

Many drugs are well absorbed by the gastrointestinal tract. The small intestine represents the principal site of drug absorption. In this study, we evaluated the absorption characteristics across the intestinal membranes of daidzein. It was found that $\mathrm{pH}$ dependence of absorption was observed in the $\mathrm{pH}$ range of 5.5-7.4. The accumulation absorption amount and $P$ app of the mucosal to serosal was highest at $\mathrm{pH}$ 7.4. One interpretation for this result is that daidzein has a phenolic hydroxyl group, which is weakly acid, thus higher $\mathrm{pH}$ may increase its solubility.

Borneol was applied to the present study to improve daidzein absorption in the intestine. The results indicated that borneol enhanced the bioavailability of daidzein by enhancing its permeability. 


\section{ACKNOWLEDGMENTS}

The work was supported by the Shanghai Municiple Committee of Science and Technology (Grant No. 07DZ19714), and the National Basic Research Program of China (973 Program), No. 2007 B 936004.

\section{REFERENCES}

[1] Coward L, Barnes N, Setchell KDR, Barnes S (1993) J Agric Food Chem 41:1961-1967. doi:10.1021/jf00035a027

[2] Adlercreutz H (1995) Environ Health Perspect 103:103-112. doi:10.2307/3432518

[3] Setchell KDR, Lawson AM, Borriello SP (1981) R Harkness Lancet 2:4-7. doi:10.1016/S0140-6736(81)90250-6

[4] Wilcox JN, Blumenthal BF (1995) J Nutr 125:631S-638S

[5] Fatemeh R, Christy D, Miseon P (2003) Arch Microbiol 180:11-16. doi:10.1007/s00203003-0551-6

[6] Zhang Y, Song T, Cunnick J, Murphy P, Hendrich S (1999) J Nutr 129:399-405

[7] Xu X, Wang H, Murphy P, Cook L, Hendrich S (1994) J Nutr 124:825-832

[8] King R, Bursill D (1998) Am J Clin Nutr 67:867-872

[9] Watanabe S, Yamaguchi M, Sobue T, Takahashi T (1998) J Nutr 128:1710-1715

[10] Shelnutt S, Cimino C, Wiggins P, Badger T (2000) Cancer Epidemiol Biomarkers Prev 9:413-419

[11] Setchell K, Brown N, Desai P (2001) J Nutr 131:1362S-1375S

[12] Setchell K, Faughnan M, Avades T (2003) Am J Clin Nutr 77:411-419

[13] Setchell K, Brown N, Desai P (2003) J Nutr 133:1027-1035

[14] Lee VHL, Yamamoto A (1990) Adv Drug Deliv Rev 4:171-207. doi:10.1016/0169409X(89)90018-5

[15] Aungst BJ (2000) J Pharm Sci 89:429-442. doi:10.1002/(SICI)1520-

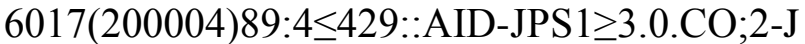

[16] Asada H, Douen T, Waki M, Adachi S, Fujita T, Yamamoto A (1995) J Pharm Sci 84:682687. doi:10.1002/jps.2600840604

[17] Wang J, Chow D, Heiati H, Shen WC (2003) J Control Release 88:369-380. doi:10.1016/S0168-3659(03)00008-7

[18] Janes KA, Calvo P, Alonso MJ (2001) Adv Drug Deliv Rev 47:83-97. doi:10.1016/S0169409X(00)00123-X

[19] Sakuma S, Hayashi M, Akashi M (2001) Adv Drug Deliv Rev 47:21-37. doi:10.1016/S0169-409X(00)00119-8

[20] Lee VHL, Yamamoto A, Kompella UB (1991) Crit Rev Ther Drug Carrier Syst 8:91-192

[21] Xiao YY, Ping QN, Chen ZP (2007) Int J Pharm 337:74-79. doi:10.1016/j.ijpharm.2006.12.034

[22] Grass GM, Sweetana SA (1998) Pharm Res 5:372-376. doi:10.1023/A:1015911712079

[23] Saitoh H, Aungst BJ (1995) Pharm Res 12:1304-1310. doi:10.1023/A:1016217505990

[24] Shono Y, Nishihara H, Matsuda Y, Furukawa S, Okada N, Fujita T (2004) J Pharm Sci 93:877-885. doi:10.1002/jps.20017

[25] Liang E, Chessic K, Yazdanian M (2000) J Pharm Sci 89:336-345. doi:10.1002/(SICI)1520-6017(200003)89:3 $\leq 336:$ :AID-JPS5 $\geq 3.0 . C O ; 2-M$

[26] Eagling VA, Profit L, Back DJ (1999) Br J Clin Pharmacol 48:543-552. doi:10.1046/j.1365-2125.1999.00052.x 
[27] Faassen F, Vogel G, Spanings H, Vromans H (2003) Int J Pharm 263:113-122. doi:10.1016/S0378-5173(03)00372-7

[28] Zhang L, Zheng Y, Chow MS, Zuo Z (2004) Int J Pharm 287:1-12. doi:10.1016/j.ijpharm.2004.08.020

[29] Shen Q, Lin Y, Handa T, Doi M (2006) Int J Pharm 313:49-56. doi:10.1016/j.ijpharm.2006.01.020

[30] Allred CD, Twaddle NC, Allred KF, Goeppinger TS (2005) J Agric Food Chem 53:85428550. doi:10.1021/jf051246w

[31] Janning P, Schuhmacher US, Upmeier A, Diel P, Michna H, Degen GH (2000) Toxicokinet Metab 74:421-430

[32] Qiu F, Chen XY, Song B, Zhong DF, Liu CX (2005) Acta Pharmacol Sin 26:1145-1152. doi:10.1111/j.1745-7254.2005.00187.x

[33] Zheng Y, Lee SO, Verbruggen MA, Murphy PA, Hendrich S (2004) J Nutr 134:2534-2539 